appetite may often mislead. If this is so, then the first object in the treatment of obesity should be to get the patient active and increase the daily energy expenditure. Too little attention is paid to this nowadays. In the past it has often been stated that by walking hard for half an hour in the morning and again for half an hour in the evening an obese person may burn off I oz. fat. This fact has been well publicized, and the effect is disheartening. If, however, the procedure is continued for a year, then over $20 \mathrm{lb}$. of fat or its equivalent will have been oxidized. This amount is not negligible. More important, this regular increase in daily energy expenditure may set the appetite-regulating mechanism aright and thereby provide the necessary conditions for the advice given by dietitians to be practical.

The sedentary nature of so much of modern industrial life necessitates a new appraisal of daily energy-expenditure rates. Much more attention is needed to the problem of the energy costs of recreations. Our Nutrition Society might begin in a practical way. I would suggest, in all seriousness, to members of the Programmes Committee who may be here that they no longer arrange our meetings on Saturday afternoons. This is a time when all of us might be employed expending calories more rapidly and to the betterment of health.

\title{
REFERENCES
}

Bowser, L. J., Trulson, M. F., Bowling, R. E. \& Stare, F. J. (1953). F. Amer. diet. Ass. 29, II 93. Durnin, J. V. G. A. (1956). Proc. Nutr. Soc. 15, 89.

Edholm, O. G. (1956). Proc. Nutr. Soc. 15, 80.

Edholm, O. G., Fletcher, J. G., Widdowson, E. M. \& McCance, R. A. (1955). Brit. F. Nutr. 9, 286.

Garry, R. C., Passmore, R., Warnock, G. M. \& Durnin, J. V. G. A. (I955). Spec. Rep. Ser. med. Res. Coun., Lond., no. 289.

FAO: Committee on Calorie Requirements (1950). F.A.O. mutr. Stud. no. 5.

FAO (1955). The State of Food and Agriculture 1955. Review of a Decade and Outlook. Rome: Food and Agriculture Organization of the United Nations.

Lehmann, G. (1953). Praktische Arbeitsphysiologie. Stuttgart: George Thieme.

Mayer, J. (1955). In Weight Control. Ames, Iowa: Iowa State College Press.

Mahadeva, K., Passmore, \& Woolf, B. (r953). Y. Physiol. r21, 225.

Müller, E. A. (1953). Quart. F. exp. Physiol. 38, 205.

Passmore, R. \& Durnin, J. V. G. A. (1955). Physiol Rev. 35, 801.

\section{Energy expenditure in the elderly}

\section{By J. V. G. A. Durnin, Institute of Physiology, University of Glasgow}

It is perhaps not immediately obvious why age itself should exert an independent effect on energy expenditure. May it not be that changes in weight or in surface area, with a different disposition in the mass of active tissue, are the chief means by which the energy output is altered?

For example, in a specific exercise one might think that energy expenditure would be related simply to, say, the weight of active tissue, such as muscle, as distinct from inactive tissue, such as bone and fat, and that, if results could be expressed as $\mathrm{Cal} . / \mathrm{kg}$ of this active tissue, then age might show almost no effect. This may indeed be true for any particular controlled exercise, such as lifting a load of moderate 
weight. But other factors become important when we consider total daily energy expenditure. The young use many extraneous movements in their work and play and may indeed spend more energy in doing some tasks than adults. On the other hand, the old may use more energy in standardized exercise than the young; they may be less efficient with less perfect nervous and muscular co-ordination.

There are many possible reasons for any differences that may exist in the energy expended by different age groups in the population. The problem of rates of daily energy expenditure is such a vast one that, with the limited knowledge available, a tendency to vagueness is inevitable in a short discourse on energy expenditure and age. It is only necessary to think of the variations in energy expenditure possible in any one age group! There are innumerable, differing types of occupation carried out by people of vastly differing weights, under all sorts of external conditions, mechanical and climatic, and each factor may be influenced over and above by age. On the question of age alone, even if we restrict ourselves to an upper limit of 70 , how can we know what is a 'normal' elderly man? What is 'old age'? Is it a disease? Does it necessarily involve changes in joints, muscles, in circulatory and respiratory tissue? What percentage of elderly men have detectable changes in these tissues? If we can find no abnormality by a thorough clinical examination of a man of 70 , including X-ray examination and electrocardiography, is this usual or unusual? The problem seems infinitely complicated.

However, in practice the differences in total energy expenditure with age may not be very large. There can be no doubt that many occupations, formerly thought of as 'heavy', are becoming much less so owing to increasing mechanization. It seems as if this trend will inevitably continue and, in a fairly short time, there will probably be only a very small proportion of the working population engaged in 'heavy' work. Almost all methods of earning a living will require only sedentary or light work. Thus, the total energy expenditure will tend to become much more uniform, if working hours only are considered. This levelling-down in the amount of essential manual work will clearly have an effect on the energy expenditure of elderly people in relation to other groups of the population. At present, there is a marked difference of opinion about the extent to which energy expenditure decreases with age. The Food and Agriculture Organization of the United Nations (FAO: Committee on Calorie Requirements, 1950) recommended a decrement of $7.5 \%$ of the requirement at age 25 for each ro years beyond this age. The report of FAO/WHO: Joint Expert Committee on Nutrition (1955) states that the Food and Nutrition Board of the National Research Council in America recommends altering this decrement to a $5 \%$ reduction for each decade over 25 . In Britain, a $3 \%$ decrement is suggested as being nearer the mark.

Factual information on total energy requirements is really very limited indeed, and, at least in Britain, is almost non-existent on the subject of ageing. However, if occupations are tending to become increasingly 'light' in nature, then as a corollary it might appear that any decrement with age would be correspondingly slight. There is almost certainly no physiological reason why healthy elderly people should not carry on in full employment in 'light' work, at least till the age of 70 . Their 
caloric needs, apart from recreation, will thus approximate to those of other adult age groups. The calorie allowance to cover 'recreation' is one of the important problems in the field of energy expenditure. If we leave aside children and adolescents, then the main differences in energy requirements in the several age decades of the population may be largely due to differences in the amount of energy expended in leisure activity. Almost all studies on energy expenditure have been done on men and women while they were actually at work. Only one or two (Garry, Passmore, Warnock \& Durnin, 1955; Edholm, Fletcher, Widdowson \& McCance, 1955), so far as I know, have taken the whole $24 \mathrm{~h}$ of the day into the measurement. Our knowledge then, of how people normally spend their recreational life is so limited as to make deductions very speculative. Undoubtedly youth is energetic at almost any period of the day. But there may well be surprisingly little difference from age 30 up to 50 or 60 .

There is some evidence which indirectly appears to contradict this theory. Pyke, Holmes, Harrison \& Chamberlain (1947) found the caloric value of the diets of twelve men living in a small institution, aged 60-85, whom they label 'active', to be from about 2000 to $2250 \mathrm{Cal}$./day. However, they found that twelve infirm old men, aged 6I-85, living in a large institution, consumed from 1900 to $2250 \mathrm{Cal} /$ /day. The 'active' men apparently were not very active; the degree of activity is perhaps given away by the authors' admission that 'most of them went for a walk in the afternoons'.

The diets of elderly women, living alone, were much higher in caloric value than these figures for men. Baines \& Hollingsworth (1955) found that the energy value of the diets purchased by more than 200 women, between 55 and 64 years, was $2900 \mathrm{Cal}$ //day and was as high as $2400 \mathrm{Cal}$ //day for a group of nearly sixty women of age 80 and over. These compare with values of 500-1500 Cal. for nine of the ten women, living at home, studied by Pyke et al. (1947). If the values of Baines \& Hollingsworth are even approximately representative of the population in general, then there can be very little difference in the energy intake for various ages up to about 65 , for women at least.

We have recently carried out a comparison (Durnin \& Mikulicic, 1956) of the energy expenditure of two groups of men, the one aged 20-30 years and the other aged 55-65, during four types of graded exercise. There were twelve men in each group and they were employed normally as general labourers. A full clinical history was taken and they were examined medically before the experiment. The exercises were done on an arm ergometer (Cathcart, Wishart \& McCall, 1923) and on a treadmill. One of the arm exercises was light in nature, involving an average energy expenditure of just over $4 \mathrm{Cal}$./min. The first of the treadmill exercises, walking on the level at 3.7 m.p.h., and the second arm exercise were of similar degree, the average energy expenditure being about $6 \mathrm{Cal} . / \mathrm{min}$; the second degree on the treadmill, walking on the level at $4.3 \mathrm{~m}$.p.h., was slightly heavier. One elderly man and one young man were studied simultaneously while they did the various exercises. The order in which work of the four different types was done was arranged in random fashion to eliminate any effect which fatigue or some other variable might 
have on the results. Measurements of energy expenditure were made by indirect calorimetry with the Max-Planck respirometer (Kofrányi \& Michaelis, I940; Müller \& Franz, 1952).

The mean energy expenditures for the two groups of men are shown in Table $\mathbf{I}$. It will be seen that in each instance the energy expended by the elderly men was higher than that by the young men. However, the differences between the two

Table I. Energy expenditure (Cal./min, gross) of two groups, each of twelve men

\begin{tabular}{llcc}
\multicolumn{2}{c}{ Exercise } & Elderly & Young \\
Arm ergometer & Ist degree & 4.36 & $4 \cdot 12$ \\
Arm ergometer & 2nd degree & 5.89 & 5.82 \\
Treadmill & Ist degree & 6.68 & $5 \cdot 72$ \\
Treadmill & 2nd degree & 8.50 & $7 \cdot 04$
\end{tabular}

groups while doing each of the arm ergometer exercises were not statistically significant. On the other hand, in each of the treadmill exercises the differences between the two groups were highly significant. It is possible that the higher rates of energy output by the older men were due in part to their being heavier than the younger group. The average weight of the young men was $64 \mathrm{~kg}$, that of the older men $68 \mathrm{~kg}$; this difference was very largely caused by one excessively heavy man, and the weights of the older men, exclusive of this one, were almost identical with those of the younger men. However, even a difference of $4 \mathrm{~kg}$ in the respective weights would have a barely discernible effect on the results.

It seems from these values that it is not necessarily the heaviness of the work which causes the difference to arise. The second degree of work on the arm ergometer and the first degree on the treadmill each had a similar metabolic cost. Yet there was a difference between young and old in the walking exercise but not in the arm exercise. In the more energetic degree of walking, the difference between the two groups was much more marked. The explanation may be that it is easier for elderly men to use, even quite vigorously, restricted muscle groups such as the arm and shoulder muscles, than to use the larger muscle masses required in walking. Walking also involves more co-ordination of joints and control of balance, and these may perhaps be less perfectly regulated in the elderly than in the young. The significance of this finding may be of some practical application in industry-it may be quite possible for elderly men to be employed in fairly strenuous work if it does not involve gross movements of large parts of the body.

In the present state of knowledge in this particular field of energy expenditure, it is only possible to theorize. Keys (1949) states that 'the number, vigour and extent of muscular movements which portray an "active" old man resemble those of a "sedentary" young man'. This statement may possibly be true, although perhaps one should define what is meant by an old man. My impression is that most elderly men might easily correspond, energetically, to young men of the moderately sedentary type. But then, so do most young and middle-aged men. The great majority of us lead lives that are very largely sedentary. We need much more information on 
how elderly people spend their daily lives and how energetic a life they may be capable of leading before we can adequately discuss this whole question.

\section{REFERENCES}

Baines, A. H. J. \& Hollingsworth, D. F. (1955). Proc. Nutr. Soc, 14, 77.

Cathcart, E. P., Wishart, G. M. \& McCall, J. (1923). F. Physiol. 58, 92.

Durnin, J. V. G. A. \& Mikulicic, V. (1956). F. Physiol. r3r. (In the press.)

Edholm, O. G., Fletcher, J. G., Widdowson, E. M. \& McCance, R. A. (1955). Brit. $\mathscr{~}$. Nutr. 9, 286.

FAO: Committee on Calorie Requirements (I950). F.A.O. nutr. Stud. no. 5.

FAO/WHO: Expert Committee on Nutrition (1955). Tech. Rep. Wld Hlth Org. no. 97.

Garry, R. C., Passmore, R., Warnock, G. M. \& Durnin, J. V. G. A. (1955). Spec. Rep. Ser. med. Res. Coun., Lond., no. 289 .

Keys, A. (1949). Nutr. Abstr. Rev. r9, I.

Kofrányi, E. \& Michaelis, H. F. (I940). Arbeitsphysiologie, II, I48.

Müller, E. A. \& Franz, H. (1952). Arbeitsphysiologie, 14, 499.

Pyke, M., Holmes, S., Harrison, R. \& Chamberlain, K. (1947). Lancet, 253, 46r.

\section{Energy expenditure in athletic activities}

\section{By H. R. NolTie, Department of Physiology, School of Medicine, University of Leeds}

Textbooks on the physiology of muscular activity now contain so much information on the energy expenditure during athletic activities (e.g. that of Karpovich, I953) that anyone interested may read them with profit. On the present occasion, therefore, I shall deal rather cursorily with recorded results of a few activities and dwell rather on incidental points of interest. First let us look at a few general points.

The practical and theoretical difficulties of estimation of energy output based on measurement of respiratory exchange are well known to all who have seriously considered the problems. Apart from the convenience of having results in calories for comparison with those of dietary surveys, one might, for most purposes, use figures for oxygen consumption. These are liable mainly to practical, not so much to theoretical, errors of determination and interpretation.

And one ought always to consider whether the real cost, over and above that for maintaining the resting state, is required, or whether the current energy expenditure is sufficiently accurate. This point is a source of great confusion in the literature. Comparatively few authors have measured the oxygen debt (or postulated none) and most have thus been unable to calculate the total as distinct from the current cost of the activity. Probably a good deal of the real variation between individual performers is thereby lost.

Many estimations have, for the purpose of convenience in recording or for accurate control of speed, been made using treadmills or ergometers in the laboratory; yet almost no results have been published validating the transfer of results to out-of-doors activities. Campbell (1924) found that the $\mathrm{O}_{2}$ uptake for one subject running on the road and on a treadmill was about identical (Table I), which would validate generalizing. I have found that the $\mathrm{O}_{2}$ uptakes were not significantly different for a trained runner at a speed of $7 \frac{1}{2}$ m.p.h. on the cinder track and on a treadmill 